\title{
Comprehensive Review on Phytochemistry, Ethnobotanical, Bioactivities and Medicinal Mysteries of Ougeinia oojeinensis (Roxb.) Hochr
}

\author{
Ashwani Tiwari, Atul Patel, Sarika Shrivastava, Sarita Karole*, Usha Vishwakarma, Prakash Mishra \\ Oriental College of pharmacy, Raisen Rd, Patel Nagar, Bhopal-462022, (M.P.), India
}

Article Information

Received 2 Nov 2019

Received in revised form 22 March 2020

Accepted 27 March 2020

Keywords:

Ougeinia oojeinensis,

Fabaceae,

Secondary metabolites,

Desmodium oojeinense,

Ougeinia dalbergioides

Corresponding Author:

E-mail : simrankare@gmail.com

Mob.: +917987710368

DOI: 10.20510/ukjpb/8/i2/1586230488

\begin{abstract}
Various parts of plants such as leaf, stem, roots and barks were used as medicines in auyrveda, siddha, unani and homeopathic treatments. As only few studies are done on such plant, the purpose of this current review is to make accessible till date information on, botany, morphology, ecological biodiversity, therapeutic uses, phytochemistry and pharmacological activities on diverse parts of Ougeinia oojeinensis. This review was assembled using technical literature from electronic search engine such as Springerlink, BioMed Central, PubMed, Scopus, ScienceDirect, Scielo, Medline and Science domain. Supplementary texts were obtained from books, book chapters, dissertations, websites and other scientific publications. O. oojeinensis commonly known as Tinsa, is rich in secondary metabolites, which impart incredible medicinal uses to the plant. The active constituents extracted from $O$. oojeinensis are genistein, ougenin, dalbergioidin, kaempferol, lupeol, Ferreirin, neophellamuretin, orobol, wedelolactone, homoferririn isoflavanone and betulin etc. The uses of bark are astringent, acrid, cooling, stimulant, anti-inflammatory, constipating, anthelmintic, sudorific, depurative, urinary astringent, styptic, febrifuge and rejuvenating. The extract of the whole plant showed anti-inflammatory, hypotensive action, antioxidant activity, hepatoprotective, anthelmintic, hypoglycemic and wound healing activities. There is a need to isolate the active constituents, their biological test, experimental defense, molecular mechanisms and legalization of there therapeutic uses of $O$. oojeinensis. The gathered detail will be obliging to determine the study protocol for current drugs and Ayurvedic formulation extension in the remedial and luxury a variety of ailments. Clinical trials for the reported preclinical studies should be executed immediately to further validate the claims on humans.
\end{abstract}

\section{Introduction}

Herbal formulations are medicinal preparation of one or more herbs present in specified quantities to give the benefits meant for cosmetic, diagnose and to mitigate diseases of human beings or animals ${ }^{1}$. It is well known as botanical medicine or phytomedicine. Earlier in twentieth century, the herbal medicine was found to be the prime medication system as antibiotics or analgesics were inaccessible. Increasing in the use of an allopathic system of medicine due to its high therapeutic effect and herbal medicine slowly lost their popularity among the common people. For example, Curcuma is used traditionally in
Chinese Medicine for more than two thousand years to cure antiinflammatory and robust antioxidant ${ }^{2,3}$. About $70-80 \%$ people are still consuming herbal medicine for their primary health because of the minimum side effect and better consistent with the human body ${ }^{4}$

Herbal medicine has gained momentum and is more effective as compared to synthetic drugs. Medicinal plants form a huge group of inexpensively significant plants that provide the essential raw materials for indigenous pharmaceuticals ${ }^{5}$. Plant products still remain the most important source of pharmaceutical agents used 
in conventional medicine ${ }^{6}$. According to the $\mathrm{WHO}$ the primary step for recognition and purification of herbal drugs is the pharmacognostic (macroscopic and microscopic) studies which are necessary for any phyto pharmaceutical products used for standard formulation ${ }^{7}$. Preliminary phytochemical studies are obliging in finding out chemical constituents in the plant material that may fine lead to their quantitative estimation ${ }^{8,9}$. Lately more concentration has directed towards the extracts and bioactive compounds are isolated from accepted plant species. In the current age of drug development and newly discovered drug molecules, a lot of plant products are judgeon the basis of their ordinary uses.

The healing ability of medicinal plants are due to the occurrence of various multifaceted chemical substances of different compositions which happen as secondary metabolites ${ }^{10}$. The most significant of these bioactive constituents of plants are steroids, tannins, alkaloids, flavonoids and phenolic compounds. Therefore, it is enviable to know the phytochemical constituents of plant material before checking its effectiveness for the medical purpose. Plants are also main natural sources of medicinal compounds in the present pharmacopoeias ${ }^{11}$. Indian Materia
Medica consist about 2000 drugs of natural origin and most of them are leading from various conventional system and myths practices $^{12}$. However, there are large numbers of plants, which have not been mentioned in these reports, in malice of their usage in the conventional and folk medicinal systems.

O. oojeinensis belongs to the family Fabaceae (Fig 1). It is a valuable timber and fodder species restricted to India mostly in the outer Himalayas and sub-Himalayan tracts from Jammu to Bhutan. The natural forests containing this tree have been severely degraded by timber exploitation. Commonly it is known as Tinsa, Sandan, Panjan ${ }^{13,14}$. The extract of the complete plant of $O$. oojeinensis were used as anti-inflammatory, analgesic, hepatoprotective, antioxidant, anthelmintic, antidiabetic hypoglycemic and wound healing activity. Phytochemical investigation on the $O$. oojeinensis have reported the existence of lupeol, hydroxlupeol, betulin and isoflavanones such as dalbergioidin, homoferreirin and ougenin. The bark and leaves are used in the cure of jaundice, diabetes dysentery, urorrhagia, verminosis, leprosy, diarrhoea, leucoderma, haemorrhages, fevers, ulcers etc ${ }^{15}$.
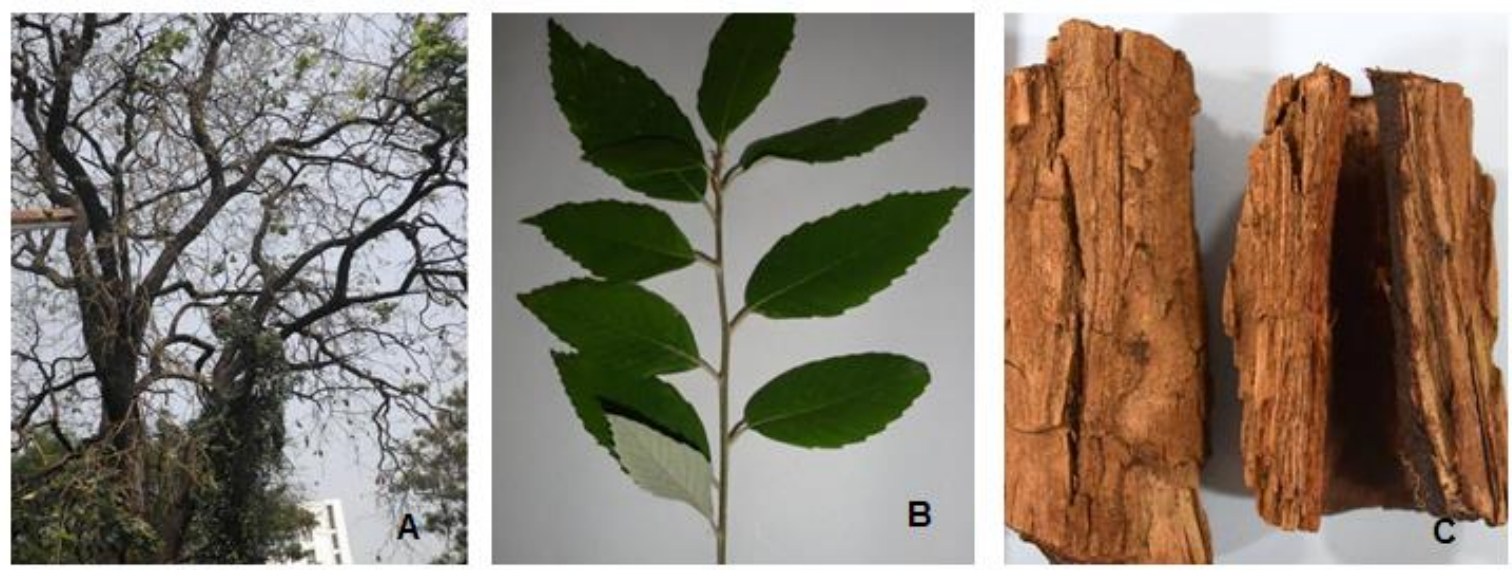

Fig 1: Ougeinia oojeinensis (A) Plant, (B) Leaves, (C) Bark

The systemic classification of $O$. oojeinensis consists of domain: Eukaryota, Kingdom: Plantae, Subkingdom: Phanerogamia, Division: Angiospermia, Phylum: Tracheophyta, Class: Dicotyledons, Sub-Class: Calyciflora, Order: Fabales, Family: Fabaceae and Synonyms: Desmodium oojeinense (Roxb.) $\mathrm{H}$. Ohashi, Ougeinia dalbergioides Benth.

The vernacular names of the plant are Hindi: sandam, terrichcha, sandan, timsa, tinnas, tinsa, Kannada: kari-mutal, Kurimutala, Marathi: syandan, kaala palaas, kalapalas, tanach, tewas, thanach, Sanskrit: sejanduna, tinisa-segandun, trinisha, tinisa, tinisa sejanduna, akshaka ect, Telugu: tella-motuku, adavicikkudu, atimuktamu, nemmichettu, Malayalam: malavenna, malahonney, nemi, totukara, Tamil: narivengai, naiponai, tella-motuku, Tibetan: ti ni sa, Bengali: pandan, bandhan. Therefore, in this study, the ethnopharmacological review of $O$. oojeinensis was carried out aimed at providing a detailed précis of the botany, ethnomedicinal uses, pharmacological activities and chemical composition of the species.

\section{Research methodology}

To recognize pertinent information on the phytochemistry, botany, medicinal uses and biological activities of $O$. oojeinensis, a review was amassed based on scientific literature from a variety of sources including Google Scholar, Science Direct, PubMed, Scielo, Springerlink, Google Patents, Web of Science, SciFinder, Scopus, Espacenet, BioMed Central (BMC) and Medline. The keywords used for recognition of relevant data included dissimilar scientific name and synonyms, common English names, and the terms: biological activities, ethnobotany, medicinal uses, medicinal, ethnopharmacology, pharmacology, phytochemistry and therapeutic value, $O$. oojeinensis, Desmodium oojeinense (Roxb.) H. Ohashi, Ougeinia

Pharm \& Biosci J. 2020: 8(2); 28 
dalbergioides Benth, tinsa, sandan ect. Further literatures were finding from books, book chapters, theses, websites and conference proceedings.

\section{Occurrence and distribution}

O. oojeinensis found in the outer Himalayas and sub-Himalayan tracts from Jammu to Bhutan up to an altitude of $1500 \mathrm{~m}$ and extending through the whole of northern and central India into the greater part of Deccan peninsula. It is an important species in Uttar Pradesh and Madhya Pradesh ${ }^{16}$.

\section{Ecology}

O. oojeinensis is native to sub-tropical regions of the India. It is commonly found in elevations of $300-1500 \mathrm{~m}$. At higher elevations they remains a small tree. The best mean annual temperature in its habitat ranges varies from $20-47^{\circ} \mathrm{C}$ with a relative humidity from $49-90 \%$. The most rainfall takes place in the range from $950-1900 \mathrm{~mm}$. This species is not easily available in wet regions. Characteristic of limestone soils, sandan grows best on dry exposed sites and eroded hills ${ }^{17}$. It also occurs on red clay, black cotton, alluvial soil and rocky soil. Its optimum growth and greatest size is attained in the lowlands on alluvial soils Sandan is a part of mixed deciduous and sal (Shorea robusta) forests. It is combined with pines at the higher limits of its elevation range.

\section{Morphology}

O. oojeinensis is a medium sized semi-deciduous tree, commonly obtain $40-50 \mathrm{~cm}$ in diameter breast height (DBH) and 7-14 meters in height ${ }^{17}$. The stem is many time crooked, but in some areas the tree is straight. The bark is changing from its pale pinkish-brown to dark bluish gray, is a little rough and exfoliates in uneven thin soft scales. Leaves are generally pinnately trifoliate, smooth above and lightly pubescent below the obovate leaflets are generally 6-12 cm long and $2-15 \mathrm{~cm}$ wide, but the size differ greatly and entire Leaf margins.

The light-pink to white flowers appear in the clusters from February to May. The preceding years branches mostly do not bear flowers. Branches bearing flowers are leafless, while remaining retain leaves. Flowering trees are conspicuous and afford beautiful sight. Pods have a distinct seam, are $5-10 \mathrm{~cm}$ long and $1 \mathrm{~cm}$ wide. They mature and become ripen in May to June and fall chiefly in June. Normally, pods remain closed until seeds germinate. Mature pod yields 2-5 viable seeds. The smooth brown seeds are 10-12 mm long and $5 \mathrm{~mm}$ wide. Trees do not seed heavily each year ${ }^{17}$.

\section{Microscopic characters}

The transverse section of bark shows outer region of rhytidome is made up of of 6 to 7 rows of rectangular cells of cork, followed by 2 to 3 rows of groups of stone cells and sclerides. Pentagonal, hexagonal or polygonal cells of rhytidome traverse with different groups of thin walled fibres, compressed phloem, groups of empty resin duct and biseriate medullary rays. Medullary rays and Parenchymatous cells embedded with starch grains and have prismatic calcium oxalate crystals. Rhytidome differing with 6 to 8 layers of irregular, lignified cell of powdery layer, followed by 6-7 covering of rectangular cells of cork. Below this group 2-5 covering of a stone cells were observed. Secondary phloem consist of somewhat polygonal to oval shaped cells traverse with different groups of thin walled fibres, groups of resin duct, compressed cells of biseriate medullary rays and phloem.

Phloem parenchyma and medullary rays embedded with simple, compound, oval starch grains and prismatic crystals of calcium oxalate $^{18}$. The root is circular in sectional view has thin epidermal layer with prominent cuticular layer. The cortex is homogenous and parenchymatous. The cells are thin walled and loosely arranged. Tannins and crystals are abundant in the cortical cells. The vascular system consists of central two or three small masses of xylem elements and thin layer of phloem elements. Outer to the central masses occur as continuous wide cylinder of xylem and phloem. The xylem cylinder has several radial chains of thick walled angular vessels and thick walled lignified fibers. Outer to the xylem cylinder is completely ensheathed by thick sclerenchyma boundary within the phloem zone; there are wide, circular secretory cavities. Calcium oxalate crystals are fairly common in the cortical cells. The crystals are "prismatic type" of rectangular, cuboidal and double pyramidal ${ }^{19}$.

\section{Phytochemical constituents}

Leaves and heartwood contained the dalbergioidin, homoferreirin and ougenin. Leaves, in addition, contained quercetin, kaempferol and leucopelaragonidin. Stem bark gave the lupeol and betulin. The bark contains $7 \%$ tannins. It also contains Genistein, Ferreirin, neophellamuretin, orobol, wedelolactone ${ }^{16}$

\section{Medicinal/ traditional uses}

O. oojeinensis yields a valuable timber. Wood air seasons slow without more degradation. The wood does not require preservative treatment. It is little difficult to work, but turns well and readily takes polish. Though originally considered it is difficult to peel, it is now frequently utilized for the plywood ${ }^{20}$. The leaves are highly valued as cattle feed. Leaves contain $12-15 \%$ crude protein ${ }^{21}$. The bark is used as a fish poison and to reduce fevers. A plant fluid exudate is used to make a medicine to treat dysentery. The tree is a host plant for lac producing insects. The resulting shellac is of good quality 22 .

In an Ayurvedic texts, Tinishaa was used for alleviating burning syndrome during illness, while Tinisha was administered for urinary disorders, skin diseases, anaemia, and for treating obesity. It was also called as Atimuktaka, the drug for reducing obesity, which has now been equated with Hiptage benghalensis. Charaka prescribed fresh juice of bark and stalks, in prescriptions, internally for fevers, debility and as tonic for recuperation. Sushruta administered the drug internally in

Pharm \& Biosci J. 2020: 8(2); 29 
obesity, jaundice, urethral discharges, chronic skin diseases; oil of the seeds as a digestive in bilious affections. A decoction of Tinisha, in combination with other intestinal antiseptics and astringents, was administered in haemorrhagic diarrhoea and dysentery. In folk medicine, the bark is used as a febrifuge. A kino-like exudation from the incised bark is used in diarrhoea and dysentery ${ }^{16}$. The juice of the root, mixed with the powder of two fruits of black pepper, is taken in cases of eye trouble. The stembark is acrid, antiinflammatory, antispasmodic, astringent, cooling, depurative, febriguge, hypoglycemic, hypolipidemic, rejuvenating, styptic and sudorific. It is useful in the management of diabetes ${ }^{23}$.

\section{Propagation}

Ougeinia dalbergioides is generally propagated from seed. The seeds do not retain their viability for more time and should be used within 12 months of maturity. Once gathered seed should be dried properly and stored in well sealed containers. A kilogram contains $28,000-33,000$ seeds. To increase germination, pods should be broken into small fragments containing one seed and absorbed in water for 1 day before sowing ${ }^{24}$. Seed should tee sown $1 \mathrm{~cm}$ deep. Germination occurs in 3-8 days. Direct sowing is very successful and highly recommended ${ }^{17,25}$.

\section{Reported pharmacological activity}

\subsection{Anti diabetic activity}

Velmurugan et al evaluated the hypoglycemic and hypolipidemic action of extract of ethanol Ougeinia oojeinensis $(200 \mathrm{mg} / \mathrm{kg})$ bark with measurements including, body weight, blood glucose level, urine glucose level and biochemical parameters. The ethanolic extracts of powdered bark was checked for its efficacy in alloxan-induced diabetic rats. The extracts showed significant $(p<0.01)$ hypolipidemic action and antihyperglycemic action as compared to diabetic control. The constituents shows important action on blood glucose and urine glucose level. It also reduces the elevated biochemical parameters, which might be due to presence of steroids, tannins, alkaloids and triterpenoids present in that extract. Thus ethanolic constituent could be served as best oral hypoglycemic agents and seems to be promising for development of phytomedicines for the diabetes mellitus ${ }^{26}$.

Samyal et al extracted different parts from $O$. oojeinensis bark extracts and evaluated the effect of antdiabetic activity of fractions. The nine several fractions were gathered from ethanol extracts of $O$. oojeinensis bark. The fraction F4, F6, F7 and F8 were administered orally in Streptozotocin (STZ)-induced diabetic rats. After the administration of fractions, blood glucose amount were monitored at specific intervals of time and it was found that they were significant lowered. Glibenclamide was used as a high quality drug at a dose of $0.50 \mathrm{mg} / \mathrm{kg}$ body weight. The findings demonstrated that parts isolated from ethanol extracts of $O$. oojeinensis bark has significant antidiabetic activity in streptozotocin-induced rats compared to high quality drug ${ }^{27}$.
Samyal et al investigated the antidiabetic activity of Ougeinia oojeinensis bark and root extracts. The different doses of ethanol extracts of bark and root were administered orally in Streptozotocin (STZ)-induced diabetic rats. After the entering of extracts, blood glucose levels were observed at specific intervals of time and it was observed that they were significantly lowered. Glibenclamide was used sometimes as a high quality drug at a dose of $0.50 \mathrm{mg} / \mathrm{kg}$ body weight. The experimental data revealed that extract has significant activity of antidiabetic in streptozotocin-induced rats as compared to standard drug ${ }^{28}$.

\subsection{Antimicrobial activity}

Mandrekar et al tested antimicrobial activity of ethanolic constitute of stem bark of Ougeinia oojeinensis using agar diffusion method against 10 bacterial and 1 fungal strains. The ethanolic extract was found to have significant antimicrobial activity against all tested microbes and particularly against Salmonella typhimurium and yeast strain Candida albicans. The traditional claim that use of this plant bark has curative properties has some merit in view of the fact that the extract has phytoconstituents with potential anti-candidiasis and anti-salmonella properties $^{29}$.

Singh and Gupta evaluated the antimicrobial action and phytochemical of the methanol and aqueous extracts of leaves of Ougeinia oojeinensis. The antimicrobial activity and minimum inhibitory concentration (MIC) of the methanol and aqueous extract of Ougeinia oojeinensis leaves was checked by agar diffusion method. levels of Inhibition produced by two extract in a dose from 50 and $200 \mathrm{mg} / \mathrm{ml}$ against taken strains was observed and differentiated with those of standard drug ciprofloxacin. Both extract recorded significant activity against all the test bacteria. The maximum antimicrobial activity was exhibited by methanol extract against all the microorganisms compared to be aqueous extract $^{30}$.

\subsection{Anti-oxidant activity}

Jayadevaiah et al evaluated the in vitro anti-oxidant activity of ethanolic constituent of the stem bark of Desmodium oojeinense by different technique namely total reducing power, nitric oxide radical scavenging activity and 1,1-diphenyl 2 picryl hydrazyl (DPPH) radical scavenging activity. The extract showed significant percentage of inhibition in dose dependent manner compared to standard antioxidant sodium meta bisulphate. Our findings give evidence that crude ethanolic extract of stem bark of Desmodium oojeinense is a rich source of natural antioxidant $^{31}$

Kumar et al evaluated different extracts of seeds of Ougeinia oojeinensis for their membrane stabilizing and antioxidant effects. The Fatty acid composition was also estimated. Membrane stabilizing effect was studied by hypotonic solution induced haemolysis of erythrocyte. Antioxidant activity was studied by DPPH method at a different concentration. GCMS 
assay was generally done for petroleum ether extract with the help of Perkin Elmer Clarus-500 model coupled with CLARUS500 Mass spectrometer. Phytochemical analysis showed that methanol extract was the richest extract for the tested phytoconstituents. Different fatty acids were present in petroleum ether extract which was analyzed by GCMS. Maximum membrane stabilizing activity of seeds of Ougeinia oojeinensis showed in Methanol extract $(81.41 \pm 1.28)$ at a concentration of $1000 \mu \mathrm{g} / \mathrm{ml}$ in comparison to standard drug aspirin. From antioxidant studies, methanol extract showed maximum antioxidant activity $(91.31 \pm 1.31)$ at a concentration of $1000 \mu \mathrm{g} / \mathrm{ml}$ than other extract in comparison to standard drug ascorbic acid ${ }^{32}$.

Sahu et al evaluated the antioxidant activity of ethanolic bark constituent of Ougeinia oojeinensis on the $\mathrm{CCl}_{4}$-induced liver injury in rats. In hepatotoxic rats, liver injury was studied by checking different parameters such as catalase activity. lipid peroxidation, levels, glutathione peroxidase action and superoxide dismutase actions were employed as biomarkers of liver damage, under the controlled condition and after the administration of $100 \mathrm{mg} / \mathrm{kg}$ and $200 \mathrm{mg} / \mathrm{kg}$, respectively. Our result suggests that the ethanolic bark extract of $O$. oojeinensis showed a significant antioxidant action. Superoxide dismutase, catalase and glutathione peroxidase activity were increased, where as the lipid peroxidation is significantly reduced in the ethanolic barks extract-treated group, in compare to the $\mathrm{CCl}_{4}$ group. Therefore the ethanolic bark extract, at the aforementioned doses, showed the important protection under the $\mathrm{CCl}_{4}$-induced hepatocellular injury ${ }^{33}$.

Singh et al evaluate in-vitro antioxidant action of the methanol and the aqueous extracts of leaves of Ougeinia oojeinensis. The antioxidant action of the in vitro was measured by means of the 1, 1-diphenyl-2-picrylhydrazyl (DPPH), nitric oxide (NO) and superoxide (SOD) free radical scavenging assays. The methanol and water extracts exhibited scavenging effect with IC50 values of 125.31 and $146.12 \mu \mathrm{g} / \mathrm{ml}$ respectively for DPPH radical and $189.75 \mu \mathrm{g} / \mathrm{ml}$ and $223.77 \mu \mathrm{g} / \mathrm{ml}$ for inhibition of nitric oxide respectively. The methanolic extract and aqueous extract has scavenging superoxide free radical with the $\mathrm{IC}_{50}$ values of 177.85 and $214.69 \mu \mathrm{g} / \mathrm{ml}$ respectively. All the characteristic were found to be dose dependent ${ }^{34}$.

\subsection{Hepatoprotective activity}

Sahu and Roy examined the hepatoprotective effect of bark of ethanol extract of Ougeinia oojeinensis in male wistar albino rats treated with carbon tetrachloride. Liver injury was studied by assessing different parameters such as serum glutamate oxaloacetate transaminase, glutamate pyruvate transaminase acid phosphatase, alkaline phosphatase and bilirubin in serum. The action of administered ethanolic extract at dose of $100 \mathrm{mg} / \mathrm{kg}$ and $200 \mathrm{mg} / \mathrm{kg}$ on the high parameter was further investigated. Results of such study revealed that the suspension of ethanolic extract showed significant hepatoprotective activity $(\mathrm{P}<0.05)$ by reducing the steps of the biochemical parameters in experimental animals. The ethanolic extract of both doses afforded significant protection against $\mathrm{CCL}_{4}$ induced hepatocellular damage. Histopathological studies too, are in conformity with findings ${ }^{35}$.

Jayadevaiah et al investigate the hepatoprotective action of ethanol extract of stem bark of Desmodium oojeinense hepatotoxicity in wistar rats. The hepatoprotective action of the ethanol extract was assessed in $\mathrm{CCl} 4$ induced hepatotoxic rats.Change in injury like SGOT, SGPT, ALP and total bilirubin level were assayed in both $\mathrm{CCl} 4$ untreated and treated groups. CCl4 has increased the SGOT, SGPT; an ethanolic extract of Desmodium oojeinense has brought back the altered levels of biochemical markers to the near normal levels in the dose dependent also provided supportive evidence for biochemical analysis. Silymarin $(100 \mathrm{mg} / \mathrm{kg})$ was given as a standard hepatoprotective drug $^{36}$

Jayadevaiah et al investigated the hepatoprotective activity of ethanolic extract of Desmodium oojeinense against Paracetamol induced Hepatotoxicity in rats. Ethanolic constitute showed important $(p<0.05)$ hepatoprotective action by lowering the serum levels of different biochemical parameters such as SGOT, SGPT, ALP, total Bilirubin and by increasing the levels of total protein, in the selected model. These biochemical observations were in turn confirmed by histopathological examinations of liver group and are comparable with the standard hepatoprotective drug Silymarin (100mg/kg bodyweight i.p.) which served as a positive control ${ }^{37}$.

\subsection{Analgesic and anti-inflammatory activity}

Jayadevaiah et al investigated the analgesic and antiinflammatory activities of ethanolic extract of Desmodium oojeinense (Roxb.) in experimental rats. Analgesic activity was evaluated using acetic acid induced writhing method, while antiinflammatory activity was evaluated using carrageenan induced rat paw oedema model. Various doses of ethanolic extract of the plant $(100,200,400 \mathrm{mg} / \mathrm{kg}$ body weight) were tested for its analgesic activity and anti-inflammatory activity and the results were compared with the standard drug aspirin and diclofenac sodium respectively. Results indicate that the ethanolic extract of the plant significantly inhibited writhing movements in analgesic activity and carrageenan induced hind paw oedema in antiinflammatory activity in a dose dependent manner ${ }^{38}$.

Sahu et al screened the ethanolic and aqueous extracts of the bark of Ougeinia oojeinensis for anti-inflammatory activity. The protection of hypotonicity induced HRBC membrane lysis was taken as the measure of anti-inflammatory activity. Both the parts showed a biphasic action on the membrane stabilization. Their actions are comparable to that of high quality drug diclofenac sodium. However their action decrease with time ${ }^{39}$.

\subsection{Wound healing activity}


Gunasekaran et al evaluated the wound healing activity of aqueous and ethanol extracts of Ougeinia oojeinensis was using excision, incision and dead space wound models on albino rats, the doses selected were the $\mathrm{ED}_{50}$ values as determined in the acute toxicity studies, administered orally. Among the two extracts, the maximum activity was recorded in the ethanol extract followed by aqueous extract. However when compared with the control both the extracts were found to possess significant wound healing promoting activity ${ }^{40}$.

Sahu et al investigated the wound healing potency of ethanol and aqueous bark extracts of $O$. oojeinensis. Excision wound model was used to evaluate the wound healing activity of both the extracts on wistar rats. The rats were divided into four groups and each group has six rats. The extract was used in the form of gel (200 mg of extract incorporated with $100 \mathrm{gm}$ of Carbopol 940 to get $0.2 \% \mathrm{w} / \mathrm{w}$ gel ) daily once times, Initially the excisions of skin from rats, till the complete epithelialization. The healing of wound was assayed by the speed of wound contraction and period of epithelialization. Both the ethanol and aqueous bark extracts promote the wound healing action significantly, when compared with the control group of animals. Ethanolic extract have better wound healing capacity than the aqueous extract ${ }^{41}$.

10.7 Others

Kumar et al demonstrate the formation of various silver nanoparticles by the reduced aqueous silver metal ions during there exposure to the ethanolic extract of Ougeinia oojeinensis. The silver nanoparticles found were characterized by colour change in the reaction, UV-visible spectrum, and scanning electron microscopy. The parameters of absorption peak at 450 $500 \mathrm{~nm}$ in UV-Vis spectrum confirmed the formation of the silver nanoparticles. The size of nanoparticles synthesized differ from 5 to $100 \mathrm{~nm}$. Membrane stabilizing activity was done by the hypotonic solution whic induce hemolysis. Ethanol extract showed $79.87 \%$ activity where as AgNPs showed mild membrane stabilizing action. The antioxidant action of AgNPs was investigated by the DPPH method. Here both ethanol and AgNPs showed mild antioxidant action. Antibacterial and antifungal activities were performed by the diffusion method ${ }^{42}$

Bhat and Patel studied the nuclear behaviour in two tropical angiosperm species: Ougeinia oojeinensis and Garuga pinnata. The ray parenchyma cells are of prime importance in the wood for their physiological activities like synthesis, degradation and translocation. They play a major role during the heartwood formation, especially in the formation of phenolic compounds ${ }^{43}$.

Wankhade and Mulani evaluated the preliminary phytochemical test on leaf and bark methanolic extract of Ougeniao oojeinensis. The results of the preliminary phytochemical studies confirms the presence of carbohydrate, saponin, starch, flavonoids, steroids, alkaloids, glycosides, terpenoids and proteins in the methanolic extracts of Ougenia oojeinensis bark and leaves. This study also estimated the Rutin and Qurecetin present in the methanolic leaf and bark extract of the Ougeinia oojeinensis through HPTLC method. The solvent system used for quantification of the quercetin and the rutin was Toluene: Ethyl acetate: Formic acid (6: $4: 0.8 \mathrm{v} / \mathrm{v} / \mathrm{v})$. The maximum Rf values of quercetin and rutin were observed 0.51 and 0.04 respectively. HPTLC fingerprint analysis of leaf and bark extract of Ougeinia oojeinennsis can be used as a diagnostic tool for the correct identification of the plant ${ }^{44}$.

Bala and Uniyal described a simple binary gradient HPLC method employing a Symmetry C18 column is for the analysis of genistein, ougeinin, homoferririn, 2,4,5,7-tetrahydroxy-6-methyl isoflavone and 2,4,8-trihydroxy-6- methoxy-7-methyl isoflavone present in heartwood extract of Ougeinia dalbergioides ${ }^{45}$. The $50 \%$ ethanolic extract of Ougeinia oojeinensis stem bark showed antispasmodic action on isolated guinea-pig ileum and weak CNS-depressant effect in mice. The extract of the whole plant showed anti-inflammatory effect against carrageenin-induced paw oedema and analgesic effect in rats. The extract was devoid of diuretic, hypoglycaemic, antipyretic and anticoagulant activities. The ethanolic extract of the stembark and the whole plant showed hypotensive action in cat/dog ${ }^{16}$.

\section{Conclusion}

In the current review, we have made an endeavor to give the mophological, phytochemical, ethnopharmacological and pharmacological information on $O$. oojeinensis. The plant $O$. oojeinensis has an excellent potential against various ailments and have been experimentally and clinically utilized in both animals and man. A variety of extracts and chemical compounds of the plant have shown antioxidant, antibacterial, cytotoxic, antiinflammatory and hypoglycaemic activities ect. A huge number of compounds have been remote from $O$. oojeinensis and shown to possess assorted biological properties. There is lack of management and conservation plan from the government side. Similarly, lack of awareness of importance regarding $O$. oojeinensis among rural villagers is leading towards the destruction of this valuable species. Due to the overexploitation of one of the critically endangered plants, there is require to focus on conservation, upgradation and sustainable utilization of this wonder plant.

\section{Conflict of interest}

The authors declare that no conflict of interest is associated with this work.

\section{Author's contributions}

AT, AP, SS, SK, UV and PM contributed for the preparation of manuscript. All authors approved paper for publication.

\section{References}

1. Olabiyi AS, Nkemehule FE, Odukoya OA, Samuel TA, Ogbonnia SO. Inhibition of glycosylation as an index of Pharm \& Biosci J. 2020: 8(2); 32 
activity in plants with antidiabetic potentials. Biochem. Pharmacol. 2013; 2:181.

2. Singletary K. Turmeric: an overview of potential health benefits, Nutr. Today. 2010; 45: 216-225.

3. Wilken $R$, Veena MS, Wang MB, Srivatsan ES, Curcumin: a review of anticancer properties and therapeutic activity in head and neck squamous cell carcinoma, Mol. Cancer. 2010; 10:1-19.

4. Nagesh PL, Murlikrishnan. Evaluation of the antimicrobial activity of various concentrations of tulsi (Ocimum sanctum) extracts against Streptococcus mutans: an in-vitro study. Indian J. Dent. Res. 2010; 21: 357-359.

5. Aiyelaagbe O. Antibacterial activity of Jatropa multifida roots. Fitoterapia 2001; 72: 544-546.

6. Prince L, Prabakaran P. Antifungal activity of medicinal plants against plant pathogenic fungus Colletotrichum falcatum, Asian J. Plant Sci. Res. 2011; 1: 84-87.

7. WHO, Quality control methods for herbal materials Updated edition of Quality control methods for medicinal plant materials, 1998.

8. Rai VM, Pai VR, Kedilaya PH, Hegde S. Preliminary phytochemical screening of members of Lamiaceae family: Leucas linifolia, Coleus aromaticus and Pogestemon patchouli. Int J. Pharm. Sci. Rev. Res.2013; 21(1): 131-137.

9. Lamaeswari G, Ananti T. Preliminary phytochemical screening and physicochemical characterization of Canna indica L, Int J. Pharm. Sci. Rev.Res. 2012; 14: 76-79.

10. Karthikeyan A, Shanthi V, Nagasathaya A. Preliminary phytochemical and antibacterial screening of crude extract of the leaf of Adhatoda vasica L, Int. J. Green Pharm. 2009; 3: 78-80.

11. Kingston DG. Modern natural products drug discovery and its relevance to biodiversity conservation. J. Nat. Prod. 2011; 74: 496-511.

12. Narayana DBA, Katayar CK, Brindavanam NB. Original system: search, research or research. IDMA Bull. 1998; 29: 413-6.

13. Sharma OP.Plant Taxonomy, Seventh reprint. Tata Mc Graw-Hill Publishing Company Ltd., Delhi, 2001, 266.

14. Singh MP, Sharma AK. Text Book of Botany, 1st edition, Anmol Publication Pvt. Ltd., New Delhi, 2002, 845.
15. Samyal ML, Ahmed Z, Bhushan S. Overview of Ougeinia oojeinensis: medicinal plant. J.Chem. Pharm. Sci. 2013; 6(2): 73-77.

16. Khare CP. Indian Herbal Remedies, Springer-Verlag Berlin Heidelberg. 2004, 344.

17. Troup RS. The Silviculture of Indian Trees. Volume 1. Oxford University Press, Oxford.1921, 228-296.

18. Nirawane RB, Gurav AM, Rao G, Mangal AK, Narayanam S. Pharmacognostic evaluation of Desmodium oojeinense (Roxb.) H. Ohashi - Stem bark. J. Ayu. Med. Sci. 2017; 2(4):261-8.

19. Gunasekaran R, UshaM, Raja S,ArunachalamG. Preliminary phytochemical and pharmacognostical evaluation of ougeinia oojeinensis (roxb.) hochr root.Hamdard Medicus. 2012; 55(1):72-82

20. Krishna S, Ram swami S. Calorific values of some Indian woods. Forest Bulletin No. 79, (New Series). Chemistry, Government of India, Central Publication Branch Calcutta Pearson, R. S. and H P. Brown. 1932. Commercial timbers of India. Volume 1. Government Press, Publication branch Calcutta. 1932; p 352-356.

21. Singh RV. Fodder trees of India. Oxford \& IBH Publishing Co., New Delhi.1982; 259.

22. Pracheta, Kulshrestha S, Tripathi R. Traditional uses of medicinal plants of summer hill, Shimla.World J.Pharm. Pharm. Sci. 2017; 6(9): 826-843.

23. Tropical Plants Database, Ken Fern. tropical. theferns. info. 2019-10-31.

24. Uniyal RC, Nautiyal AR. Effect of presoaking in water in germination of Ougeinia dalbergioides seeds. Nitr. Fix. Tree Res. Rep. 1992; 10:176-177.

25. Kadambi K, Dabral SN. Studies in the suit ability of different methods of artificially regenerating forest trees. Indian Forester 1955; 81(2):129.

26. Velmurugan $C$, Sundaram $T$, Kumar RS, Vivek B, SheshadriShekar D, Kumar BSA. Anti diabetic and hypolipidemic activity of bark of ethanolic extract of ougeinia oojeinensis (roxb.) Med. J. Malaysia. 2011; 66(1): $22-26$

27. Samyal ML, Ahuja A, Ahmed Z. Evaluation of antidiabetic activity of isolated compound from ougeinia oojeinensis barks extract in diabetic rats. UK J. Pharm. Biosci. 2014; 2(5): 27-33

28. Samyal ML, Ahmed Z, Bhushan S, Bhagat A, Mishra T, Samyal M. Evaluation of antidiabetic and antihyperlipidemic effects of Ougeinia oojeinensis in diabetic rats.UK J. Pharm. Biosci. 2014; 2(1): 7-11.

Pharm \& Biosci J. 2020: 8(2); 33 
29. Mandrekar M, Desai VH, Joshi M, Sardessai Y, Joshi A. Antimicrobial activity of ethanolic extract of stem bark of ougeinia oojeinensis (roxb.) Hochr. World J. Pharm. Res. 2014; 3(5): 613-622

30. Singh J, Gupta R. Phytochemical Screening and antimicrobial activity of ougeinia oojeinensis leaves.Columbia J. Pharm. Sci. 2015; 2(2); 06-10

31. Jayadevaiah KV, Ishwar Bhat K, Joshi AB, Vijaykumar MMJ, Swetha G, Rajashekhar KV. In-vitro anti-oxidant activity of desmodium oojeinense (roxb.) $\mathrm{H}$. Ohashi. Pharmacologyonline. 2011; 3: 1119-1126.

32. Kumar D, Sanghi A, Chandra R, Arora S, Tiwari G, Mishra V.Membrane stabilizing and antioxidant activity of ougeinia oojeinensis seed extracts and their fatty acid composition. Res. J. Pharm. Biol. Chem. Sci. 2018; 9(3): 239-245

33. Sahu RK, Sharma U, Roy A, Dewangan D, Namdeo KP. The antioxidant effect of ethanolic bark extract of Ougeinia oojeinensis (Roxb.) Hochr on $\mathrm{CCl} 4$ induced liver damage. Biosci. Biotech. Res. Asia. 2008; 5(2) 783-787.

34. Singh J, Sahu RK, Prasad DN, Jangde R, Gupta R. Evaluation of in-vitro antioxidant activity of Ougeinia oojeinensis leaves. Pharmacologyonline. 2011; 2 . 1188-1195.

35. Sahu RK, Roy A. Hepatoprotective activity of ethanolic extract of ougeinia oojeinensis barks in ccl4 treated male rats. Pharmacologyonline. 2009; 2: 1-5.

36. Jayadevaiah KV, Ishwar Bhat $\mathrm{K}$, Bharathi DR. Hepatoprotective activity of desmodium oojeinense against ccl4 induced hepatotoxic rats. Impact: Ethnopharmaco. 2017;( 2): 29-32.

37. Jayadevaiah KV, Ishwar Bhat K, Joshi AB, Vijaykumar MMJ, Rawal P. Hepatoprotective activity of
Desmodium oojeinense (Roxb.) H. Ohashi against paracetamol induced hepatotoxicity.Asian J.Pharm. Health Sci. 2012; 2(2): 312-315.

38. Jayadevaiah $\mathrm{KV}$, Ishwar Bhat $\mathrm{K}$, Joshi $\mathrm{AB}$, Vijaykumar MMJ, Swetha G. Analgesic and anti-inflammatory activity of desmodium oojeinense(roxb.)h.ohashi. American J. Pharm Tech Res. 2012; 2(1): 556-563.

39. Sahu RK, Dewangan D, Roy A, Namdev KP. Antiinflammatory action of ougeinia oojeinensis (roxb.) hochr bark by HRBC membrane stabilization. Res. J. Pharm. Tech. 2008; 1(1):57-58.

40. Gunasekaran R, Usha M, Arunachalam G. Wound healing activity of Ougeinia oojeinensis (Roxb) Hochr root. J. Pharm. Res. 2011; 4(4):1195-1196

41. Sahu RK, Kulshrestha V,Kothiya S,Yadav P, Roy A. Healing potential of gel containing extract of ougeinia oojeinensis on excision wounds in wistar rats. J. Global Pharm. Tech. 2010; 2(1): 103-106

42. Kumar D, Arorab S, Abdullah, Danish M. Plant based synthesis of silver nanoparticles from ougeinia oojeinensis leaves extract and their membrane stabilizing, antioxidant and antimicrobial activities. Materials Today: Proceedings. 2019; 17:313-320

43. Bhat KV, Patel JD. Nuclear studies in relation to heartwood formation in ougeinia oojeinensis roxb and garuga pinnata roxb. Caryologia. 1980; 33: 519-526,

44. Wankhade MS,Mulani RM. chromatography finger print profiling and phytochemical investigation onleaf and bark methanolic extract of ougeinia oojeinensis. Int. J. Cur. Res. 2015; 7(2): 12665-12673.

45. Bala S, Uniyal GC. High-performance liquid chromatographic analysis of genistein and other isoflavonoids from heartwood of ougeinia dalbergioides. Phytochem. Anal. 2002; 13: 211-214. 